\title{
Learning Fuzzy Control of Nonlinear Processes
}

\author{
Vytautas KAMINSKAS, Raimundas LIUTKEVIČIUS \\ Vytautas Magnus university \\ Vileikos 8, 44404 Kaunas, Lithuania \\ e-mail: r.liutkevicius@if.vdu.lt
}

Received: January 2005

\begin{abstract}
Due to high nonlinearities and time-varying dynamics of today's control systems fuzzy learning controllers find appliance in practice. The present paper proposes a method for the synthesis of the learning fuzzy controllers where an expert knowledge about a process is applied to form a learning mechanism that is used to acquire information for the knowledge base of the main fuzzy controller. According to the proposed method an expert knowledge is used to describe how the controller should learn to control rather than to control the process. The results of experiments on heating system and level/pressure system prove the practical relevance of the design strategy of a learning fuzzy controller.
\end{abstract}

Key words: fuzzy control, nonlinear control, learning control, level control, pressure control, temperature control.

\section{Introduction}

With the increase of the computation power the more complex control algorithms can now be applied to today's highly nonlinear, sometimes even not well explored systems that are affected by unexpected internal or external disturbances, to systems whose dynamics is changing in time. Fuzzy logics (Zadeh, 1965) led to new approaches of nonlinear control algorithms where linguistic rules, expert knowledge determine the control strategies. Knowledge about the control system becomes the key think in effectiveness of fuzzy controllers. But the problem is that an expert knowledge available at the time of the synthesis of a fuzzy controller often is imprecise and sometimes much differs from actual situation so controller has to be tuned later anyway. Besides, fuzzy controllers have many parameters that have to be carefully adjusted to get sufficient performance. In cases when system identification is not used this should be done experimentally and takes plenty of time.

In this article an approach when expert knowledge is used for the synthesis of controller's learning and adaptation algorithms, their rule bases and the controller's structure rather then the rule base of the fuzzy controller is presented. This design strategy provides the fuzzy controllers with higher flexibility and versatility especially in the cases when the same controllers control the similar plants in different environment. Such systems might be for example heating-cooling systems where pipes have similar configuration but differ in size, houses are in different geographic locations. Learning and adaptation algorithms 
are capable to learn many parameters of fuzzy controller and save time for their adjustment. The performance of the proposed learning fuzzy controller is demonstrated in the practical experiments on heating system and level/pressure system.

The article is divided into three parts. The first part is the description of the structure and the synthesis of learning fuzzy controller. The two other parts show the application of the proposed fuzzy controller in real world nonlinear control problems: heating system control and level-pressure control systems.

\section{Fuzzy Controller}

Closed loop fuzzy control systems are analyzed in this article. The aim is to synthesize a learning fuzzy controller that is capable to identify and to learn the characteristics of a nonlinear plant and to used that knowledge to control that plant at various different operating modes. For this purpose a fuzzy controller composed of a knowledge base, learning mechanism and performance analysis unit is proposed (Fig. 1). Even if a large amount of expert knowledge about the process is presented, the synthesis of a tolerable fuzzy controller for this process in most cases is a challenging task due to many parameters in fuzzy controller. As research and experiments show that an expert knowledge in most cases has to be tuned in order to reach the desired performance of a controller. In order to effectively select the correct values for these parameters, adaptation and learning mechanisms have to be considered.

The proposed learning fuzzy controller differs from other learning fuzzy controllers in that it's knowledge base has not only the rule bases of the control algorithm but also the controller's scaling gains, the rule base generation data. Controller's learning mechanism is composed so that each data base in the controller's knowledge base has a separate learning algorithm in the learning mechanism and all together is capable to learn

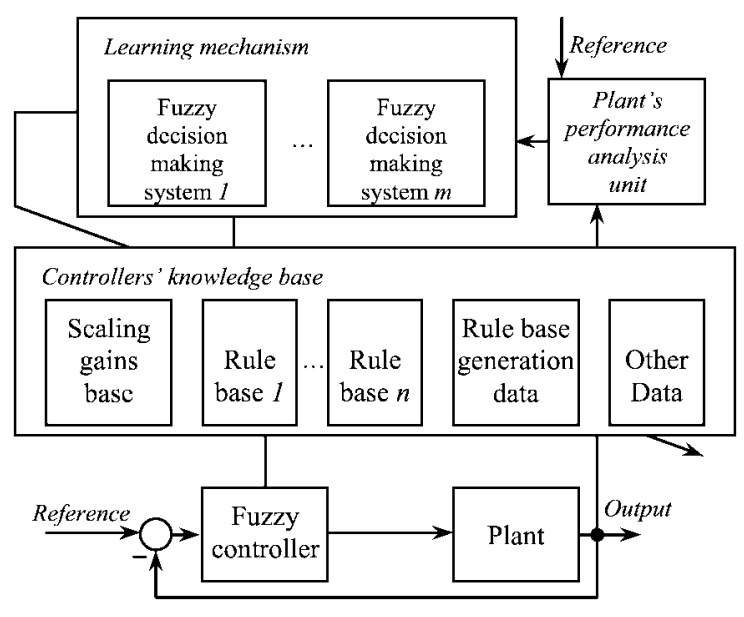

Fig. 1. Learning fuzzy control scheme. 
controller's knowledge base. This saves time for the selection and adjustment of many controller parameters.

A fuzzy controller is easier to teach if the fuzzification, inference and defuzzification mechanisms are dependent on coefficients, for example: scaling gains, centers of input membership functions, learning rates, rule base synthesis data, and so on. This data can be stored in the controller's knowledge base, which is on line adjusted by the learning mechanism, Fig. 1.

\subsection{Rule Base and Inference Mechanism}

As an expert knowledge is more convenient to represent with Mamdani type fuzzy structures (Mamdani, 1974) then with Takagi-Sugeno type structures (Takagi, 1985; Abonyi, 2003), the Mamdani type fuzzy rule bases with the rules like

$$
\mathrm{IF}\left(x_{1} \text { is } A_{1 i}\right) \text { AND } \ldots \text { AND }\left(x_{m} \text { is } A_{m i}\right) \text { THEN } y_{i} \text { is } Y_{i} \text {, }
$$

are used throughout this paper. Takagi-Sugeno fuzzy rules are more effective when parameter identification algorithms are used but not in this case. Every rule is presented by a conjunction (MIN operator) and the aggregation of the rules by a disjunction (MAX operator) (Chen, 2001; Cox, 1994). Triangular fuzzification and center of gravity defuzzification on implied fuzzy sets, calculated according to formula

$$
y_{q}^{\text {crisp }}=\frac{\sum_{i=1}^{R} b_{i}^{q} \int_{y_{q}} \mu_{\hat{B}_{q}^{i}}\left(y_{q}\right) \mathrm{d} y_{q}}{\int_{y_{q}} \mu_{\hat{B}_{q}^{i}}\left(y_{q}\right) \mathrm{d} y_{q}},
$$

are used for the calculation of crisp outputs (Passino, 1998), where $R$ is the number of rules, $b_{i}^{q}$ is the center of area of the membership function, associated with the implied fuzzy set $B_{q}^{i}$ for the $i$ th rule and integral, denoting an area under a membership function.

The rules in the controller's rule base are synthesized online from the rule base generation data which is stored in the knowledge base (Liutkevičius, 2003). This form of rules' generation reduces the number of rules in the controller's rule base and simplifies a learning process as only the rules' data but not the whole rule base has to be learnt. If controller uses several fuzzy decision making systems for input preprocessing, the rule bases of these systems might also be stored in the knowledge base and can be adjusted by the learning mechanism.

\subsection{Knowledge Base}

The essential thing during the synthesis of the fuzzy controller is to make the performance of the control algorithm be dependable on parameters that can be stored in the controller's knowledge base and can be adjusted later by controller's learning mechanism. Knowledge base can contain the information about the scaling gains of the universes of discourses of the controller's linguistic input and output variables, data bases for the on-line generation 
of control rules in fuzzy controller's rule base, learning rates, rule bases for inputs' preprocessing fuzzy decision making systems and other information concerning the use of data in the rules. At the start up of such type fuzzy controller it knows nothing about how to control the plant because its knowledge base is empty or is set to some presumptive values, so it must take some time to learn the knowledge base. Learning mechanism plays important role in the performance of the controller.

\subsection{Learning Mechanism}

The data structures of fuzzy controller's knowledge base are learnt by the controller's learning mechanism. The learning mechanism contains separate fuzzy decision making systems and the knowledge base modifiers for each element in the knowledge base that should be learnt: for example one for scaling gains, one for each rule base and etc. Depending on the process information each fuzzy decision making system of the learning mechanism calculates the adjustment values for the appropriate data and with the help of knowledge base modifier adjusts the knowledge base. Each fuzzy decision making system, described in this paper, uses triangular fuzzification, MIN-MAX inference and center of gravity defuzzification techniques. Other types might be used but the selected ones are chosen because of fast and simple calculation, essential for real time control (Driankov, 1998). The rule bases are of Mamdani type because it is easier to represent expert knowledge in such rules.

Fuzzy decision making systems in the learning mechanism calculate shift values for particular data in the knowledge base. A shift value is simply added to the knowledge base data or some rules might be used. Each fuzzy decision making system in the learning mechanism is synthesized using an expert knowledge: an expert knowledge is used to decide what inputs are essential in the learning process of a particular data structures, what the learning speed should be or how it should vary. The knowledge base can contain some parameters from the learning mechanism as well, for example learning rate. In this case the learning mechanism can slightly modify even itself. The inputs of the learning mechanism are the outputs of the plant, its errors from appropriate reference values and the outputs of the plant operation analysis unit.

\subsection{Performance Analysis Unit}

The plant's performance analysis unit operates like an input preprocessing unit for the learning mechanism and keeps track on the plant's operation, analyses data and provides the learning mechanism with relevant statistical data, like rise time, overshoot or steady state errors of process variables. The structure of the unit depends on the control task and is defined according to the expert knowledge with the purpose to provide the learning mechanism with the required information and might operate like a separate fuzzy decision making system. 


\section{Learning Fuzzy Control of Level and Pressure}

The water level and the air pressure control is a classical problem in control engineering, specific to the rectification, adsorption, and graduation technological processes, widely found in chemical and food industry. The control problems like: to maintain the water level and the air pressure at the specified set points, to decrease the overshoot of process variables during the system's transient response and to decrease the variations of the manipulated variables were analyzed in (Liutkevicius, 2003). The earlier proposed fuzzy controller had many parameters that had to be experimentally adjusted. The selection of appropriate values for these parameters took plenty of time. So the primary goal of the fuzzy controller, presented in this paper is to learn to control the plant at different operating regimes and to maintain the desired performance level learning not only the control rules, but also the scaling gains and the controller's learning rates. The aim of this part of the paper is to show the practical application of the learning fuzzy controller synthesized according to the structure, presented in Fig. 1.

\subsection{Plant}

The plant is shown in Fig. 2. Its central part is a close tank with the adjustable water level and the air pressure. The variables of the process "pressure" and "level" can be varied using the inlet water flow and/or the inlet airflow. These are varied with separate pumps $(1,2)$. The pumps are the actuators and have an electrical input-range of 0 to $10 \mathrm{~V}$. The tank has two outlets for water flow and two outlets for airflow. The exit water flow is controller by manual valves $(4 a, 5)$. These valves and the control of the water pump manipulate the stationary condition of the water flow. The manipulation of pressure is performed through the air pump (2). The change of level and/or pressure set points itself changes the dynamics of the plant. This is because water level and air pressure are dependent on each other, so the change in the air pressure affects the water level, whereas the change in the water level affects the air pressure.

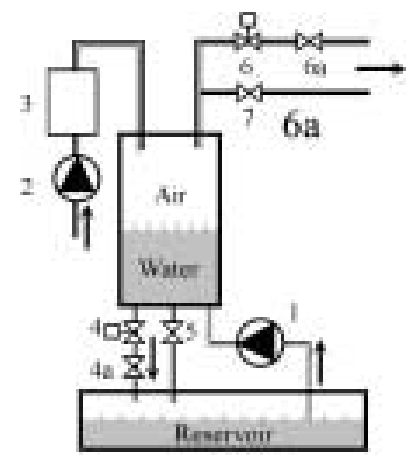

Fig. 2. Plant's structure 


\subsection{Fuzzy controller}

Learning fuzzy controller is synthesized according to the structure, presented in Fig. 1. Its simplified structure is displayed in Fig. 3.

Level/pressure learning fuzzy controller has six inputs and two outputs. The inputs are water level and air pressure reference signals, $R_{\text {level }}$ and $R_{\text {pressure }}$ respectively, level error $e_{\text {level }}$ and its change in time, pressure error $e_{\text {pressure }}$ and its change in time. The outputs are the water pump control signal $u_{\text {level }}$ and the air pump control signal $u_{\text {pressure }}$. For all these input signals the scaling gains are used and their values are stored in the controller's knowledge base. In order to achieve better performance scaling gains for the error inputs are adjusted online by controller's learning mechanism. The values of these scaling gains are dependent on the set point, so different operating regimes have their own scaling gains for the error inputs. This modification provides a better performance of the controller (see the results of experiments). The adjustment of the scaling gains allows changing the controller's sensitivity to the control errors as scaling gains make an influence to the fuzzification process, can extend or narrow the universes of discourses of the fuzzy inputs. The initial values for the errors' scaling gains are set to ones. The remaining scaling gains are chosen taking into account the physical characteristics of the plant. The outputs of fuzzy controller are values from interval $[0 ; 1]$ but the plant can take inputs from interval $[0 ; 10]$ so the scaling gains for output signals are set to 10 .

The rule bases of the controller are synthesized online from the level rule base reference values, stored in the knowledge base. The reference values are stored in the nine elements arrays. The rules have Mamdani type form because these are easier to understand and to learn with the learning algorithm used in the controller. The water level fuzzy controller's rule base is composed of total 243 rules and air pressure fuzzy controller's

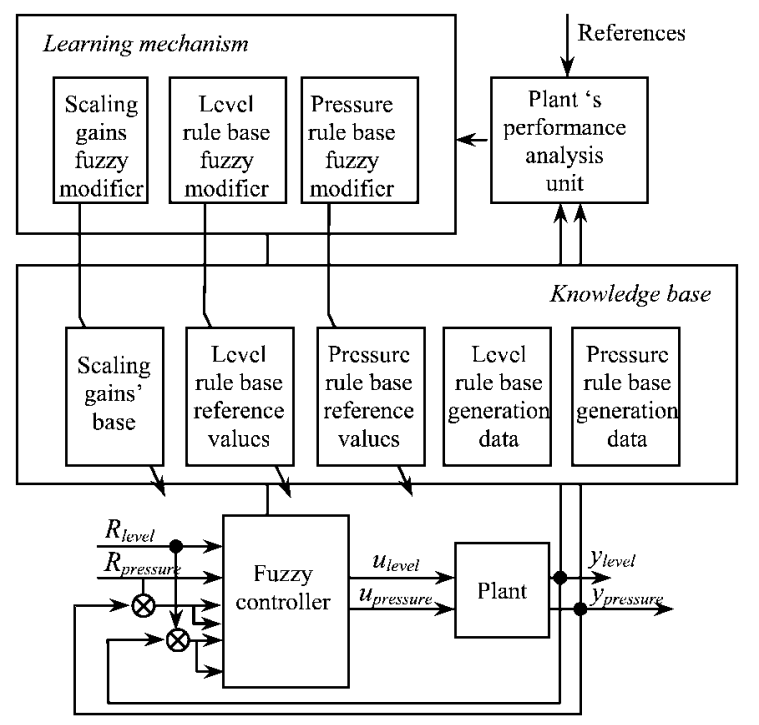

Fig. 3. Level and pressure learning fuzzy control. 
-243 rules, which are dependent on current level and pressure set points (Liutkevičius, 2003). Both rule bases are a set of nine $9 \times 3$ matrices, where water level error and air pressure error have nine membership functions each. The universe of discourse of the change of error input variable is covered with three triangular membership functions. Intervals of universes of discourses of inputs and outputs (except error inputs) are chosen from technical characteristics of the plant and experimentally tuned later. All combinations of membership functions are taken into consideration in the rule bases. The rule bases at the start up of the controller are set to zeros, this means controller knows nothing about how to control the plant, but it has its knowledge base and learning mechanism so is capable to learn to control the plant.

\section{Controller's learning mechanism}

Fuzzy controller's learning mechanism contains three fuzzy decision making systems, one for the adjustment of the scaling, the second for the level rule base's reference values and the third for the pressure rule base's reference values. As the rule base reference values are used for the online synthesis of the controller's rules, the change of these values directly affect the controller's rule base, the controller has the direct learning mechanism. The decision making systems in controller's learning mechanism also have Mamdani type rules as these allow clearly express expert knowledge how to tune the controller. The learning mechanism gets inputs from the plant's performance analysis unit: the steady state errors of process variables, their change in time and the rise time at the transient states. The outputs of the fuzzy decision making systems in the learning mechanism are the crisp values that are added to the appropriate data in the knowledge base.

For this task the knowledge base modifier is used. It also tracks the learning and adaptation process and prevents the controller from over learning (Liutkevičius, 2003).

The adjustment of the error scaling gains is organized so that level and pressure error scaling gains increase with the operating regimes. The reference level and pressure fuzzification is used to determine the operating regimes. The experiments show that at higher operating regimes the plant is not so sensitive to the variation of the active rules in the rule bases so the increase of scaling gains increase the sensitivity of the controller and it reacts to the changes in the process variables' errors faster. At lower operating regimes the plant is very sensitive to the variation of active rules so it is desirable to reduce the number of active rules decreasing the scaling gains. The learning mechanism learns nine scaling gains for level error inputs and nine for pressure error input as the universes of discourse for these inputs are covered with nine fuzzy membership functions each. The scaling gain learning mechanism tracks the use of active rules in the rule base and adjusts the scaling gains when the error fluctuates about the zero. The sufficient fluctuation of active rules around the zero error stating rule was set to $5 \%$ at the lowest operating regime and $30 \%$ at the highest.

\subsection{Experiments}

The performance of the enhanced learning fuzzy controller was experimentally tested and the results were compared with the performance of the simple fuzzy controller (Kaminskas, 2002), conventional proportional-integral-derivative controller, PID, (Kaminskas, 
2002) and the learning fuzzy controller that does not have scaling gain learning capability (Liutkevičius, 2003).

For the analysis of the controllers, 400 seconds of control data were examined. The reference values were changed every 57 seconds; the data from the plant was logged at one-second intervals. The water level and the air pressure reference signals have a step form.

The efficiency of the controllers was evaluated calculating the standard deviations of controlled and control signals according to formula:

$$
S t d=\sqrt{\frac{1}{N} \sum_{i=1}^{N}\left(x_{i}-\bar{x}\right)^{2}},
$$

where $\bar{x}$ is the reference signal, when calculating the deviation of the controlled variable, and the average of the control signal when calculating the deviation of the control signal. The performance of the controllers operating the plant at the $9.5 \mathrm{~cm}$ water level and 12 mbar air pressures are presented in the Table 1. Table 2 provides the average of standard deviations operating the plant at all tested regimes.

The response of the plant, controlled with the conventional PID controller is shown in the Fig. 4. Fig. 5 shows the response of the plant, controlled with the fuzzy controller,

Table 1

Comparison of controllers

\begin{tabular}{lcccc}
\hline \multicolumn{1}{c}{$\begin{array}{c}\text { 9.5 cm water level, } \\
12 \text { mbar air pressure }\end{array}$} & $\begin{array}{c}\text { Water level } \\
\text { error }\end{array}$ & $\begin{array}{c}\text { Air pressure } \\
\text { error }\end{array}$ & $\begin{array}{c}\text { Water level } \\
\text { control signal }\end{array}$ & $\begin{array}{c}\text { Air pressure } \\
\text { control signal }\end{array}$ \\
\cline { 2 - 5 } Controllers & 0.3187 & 0.3072 & 0.2704 & 0.0134 \\
PID controller & 0.1280 & 0.0812 & 0.0144 & 0.0010 \\
Fuzzy controller & 0.1088 & 0.0875 & 0.0517 & 0.0021 \\
Learning fuzzy controller & 0.1016 & 0.0812 & 0.0481 & 0.0017 \\
Enhanced learning fuzzy controller & & & & \\
\hline
\end{tabular}

Table 2

Comparison of controllers

\begin{tabular}{lcccc}
\hline \multicolumn{1}{c}{\begin{tabular}{c} 
Average of standard deviations $\begin{array}{c}\text { Standard deviations } \\
\text { evaluated from all tested } \\
\text { operating regimes }\end{array}$ \\
\cline { 2 - 5 } Controllers
\end{tabular}} & $\begin{array}{c}\text { Water level } \\
\text { error }\end{array}$ & $\begin{array}{c}\text { Air pressure } \\
\text { error }\end{array}$ & $\begin{array}{c}\text { Water level } \\
\text { control signal }\end{array}$ & $\begin{array}{c}\text { Air pressure } \\
\text { control signal }\end{array}$ \\
\hline PID controller & 0.6751 & 0.1634 & 0.1949 & 0.0074 \\
Fuzzy controller & 0.3008 & 0.1023 & 0.0352 & 0.0026 \\
Learning fuzzy controller & 0.1889 & 0.0908 & 0.0286 & 0.0067 \\
Enhanced learning fuzzy controller & 0.1803 & 0.0845 & 0.0224 & 0.0059 \\
\hline
\end{tabular}




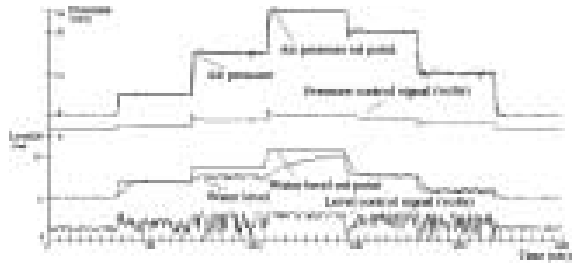

Fig. 4. PID control of the plant.

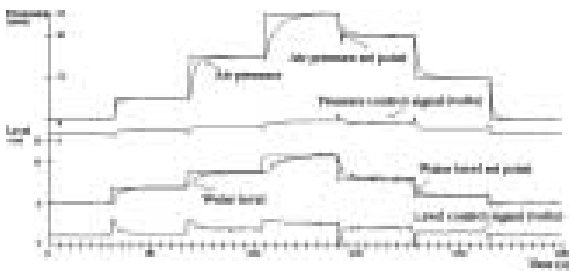

Fig. 6. Learning fuzzy control of the plant.

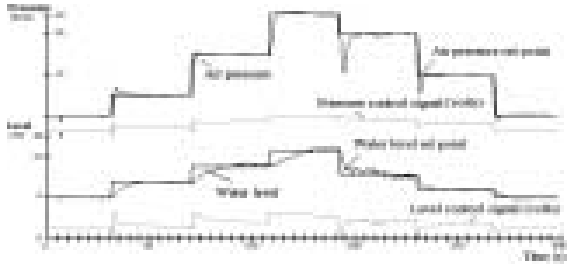

Fig. 5. Fuzzy control of the plant.

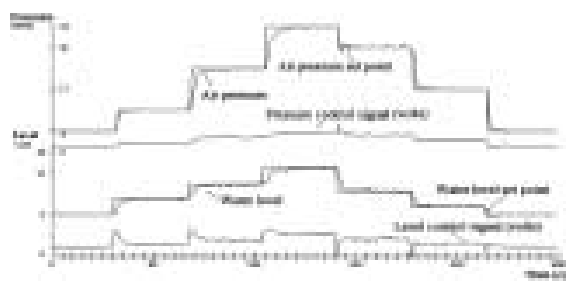

Fig. 7. Enhanced learning fuzzy control of the plant.

Fig. 6 shows the response of the plant, controlled with the learning fuzzy controller and Fig. 7 shows the response of the plant, controlled with enhanced learning fuzzy controller. The experiments on controllers were carried under the same conditions.

The experiment shows that the enhanced learning fuzzy controller provides the best results controlling the plant at different operating regimes. PID controller was tuned to operate at set points $8 \mathrm{~cm}$ and 4 mbar and from the Fig. 4 can be seen that is provides sufficient performance, but as the plant is nonlinear, at other operating regimes controller's performance degrades. PID controller's parameters have to be tuned for every other operating regime. Analyzing the overall performance of these two controllers, the water level error is 3.74 times smaller and the air pressure error is 1.93 times smaller in case of enhanced learning fuzzy controller.

Simple fuzzy controller, all parameters and the rule bases were synthesized using expert knowledge. As the plant is nonlinear and every time operates slightly different the rules and other parameters need to be adjusted. That is why learning fuzzy controllers operate better. If compared to the learning fuzzy controller, simple fuzzy controller gives 1.59 times greater water level errors and 1.13 times greater air pressure errors. The difference is because learning fuzzy controller learns to control the plant trying to reduce the process variable error. The synthesis of learning fuzzy controller is faster as there is no need for the synthesis of the rule bases.

The enhanced learning fuzzy controller helps to select the values of the scaling gains. The experiments show that good strategy may slightly improve the performance of the controller and also saves controller's synthesis time. 


\section{Learning Fuzzy Control of Heating System}

Energy consumption, environment pollution and comfort are important aspects of heating systems' control problems. The proposed in this paper fuzzy controller's with the learning mechanism design structure was applied to the synthesis of the fuzzy controller for heating system control to show its application availability. The synthesized fuzzy controller contains learning mechanism that allows adjusting the fuzzy controller to different environment and eliminates maintenance problems.

The goals of the proposed learning fuzzy controller are:

- to adjust to different environment,

- to learn to control heating system that has a similar configuration, and

- to reduce burner on/off switching rates.

\subsection{Plant}

The structure of the heating system is shown in the Fig. 8. System consists of a gas boiler (1), four way mixing valve (2), regulated with a servo motor, the water circulation pump (4) and a radiator system (3). This heating system's structure is typical for most mid size private houses. Besides, this structure can be found as subsystems in complex heating systems, where the output water temperature has to be controlled, so the control strategy can actually be widely applied.

\subsection{Learning fuzzy controller}

Simplified fuzzy controller's structure is shown in Fig. 9. The main fuzzy logic controller FLC 3 controls the boiler's heating capacity with PD characteristics. It has four input signals and one output signal. The output signal is the boiler stage $B_{\text {Stage }}$, which can get values 0,1 , and 2 , where 0 means the boiler is turned off, 1 - boiler works at half of its heating capacity, and 2 - boiler works at full heating capacity. The input signals to the controller are calculated in the preprocessing stage and are: the heating power demand,

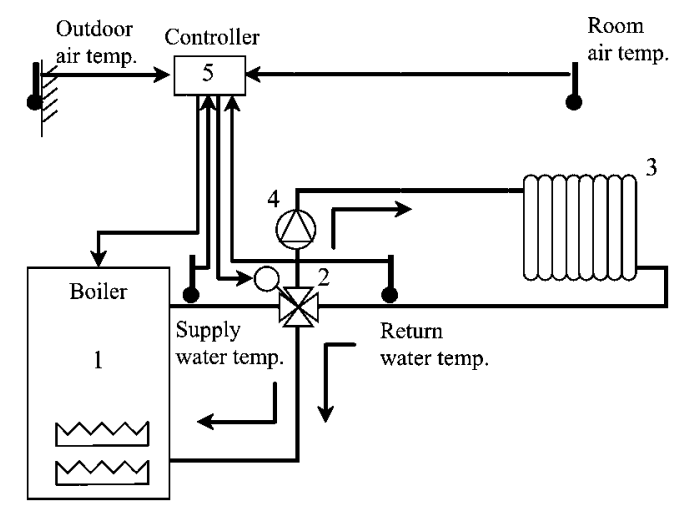

Fig. 8. Heating system control scheme. 


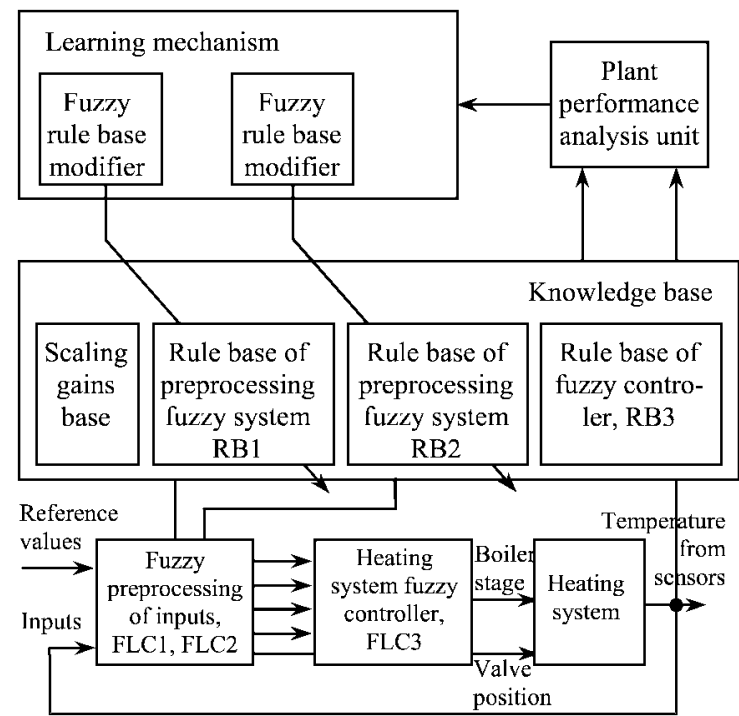

Fig. 9. Learning fuzzy control of heating system.

the room temperature error, differential of room temperature error, and the supply water temperature error. For the calculation of heating power demand and the supply water temperature error, the calculated reference output water temperature is used. Other two variables, the return water temperature and the supply water temperature, are measured. Fuzzy controller FLC 3 utilizes triangular membership functions that are arranged by Ruspini-type partition, keeping the sum of the membership degrees equal to 1 (Abonyi, 2003). The expert knowledge is used to define the controller's rule base that has 225 rules. The rules have Mamdani-type form and are generated automatically in a particular way (Liutkevičius, 2003). The fuzzy controller's inference mechanism uses the product of the degrees of memberships for the calculation of the output that is defuzzyfied using the center of gravity technique (Pasino, 1998).

Fuzzy preprocessing block $F L C 1$, depending on the outside air temperature, calculates the boiler's switching delay time and the temperature rise time, during which the premises temperature rises by $1^{\circ} \mathrm{C}$. The rule base of this input preprocessing block is initially set to zeros and is learnt during the control process.

Usually room temperature controllers have timers that allow the users to specify the reference room temperatures for the whole week or a single day. Most of them do not calculate how long it takes to rise the temperature in the premises to the desired set point. If a user wants the temperature in the room to be the desired one at the specified time, he by him self has to evaluate the rise time of the temperature in the premises. The rise time depends not only on the premises characteristics, but also on the outside air temperature, so it will be necessary to evaluate it every time the outside temperature changes. So the second fuzzy input preprocessing block FLC2 according to the reference room temperature and the outside air temperature calculates the reference output water temperature - an input to the main fuzzy controller. 
The learning process in the controller starts by analyzing the heated premise's temperature correspondence to the desired at the current moment temperature and calculation of the FLC 1 rule base correction values: delay and the rise time. At the start up of the controller the rule base $R B 2$ is initialized to the values, equal to $60^{\circ} \mathrm{C}$. This means that despite of the outdoor weather temperature and the reference room temperatures, the reference output water temperature is equal to $60^{\circ} \mathrm{C}$. But controller's learning mechanism along with the plant performance analysis unit analyses the environment, heating system's performance and corrects the rules in the rule base in order to achieve better performance. In general, the learning mechanism of the input preprocessing block FLC2 searches for the lowest output water temperature that can keep the room temperature at the desired set point taking into account the outside air temperature.

\subsection{Experiments}

The proposed learning fuzzy controller was experimentally tested and compared to the conventional proportional controller (Ogata, 1997) factory built into the boiler. For the comparison of controllers' performance, three criterions were used:

- comfort level,

- gas consumption,

- on/off switching rate of the boiler stages.

The experiments have been carried out at the similar environmental conditions. The outdoor air temperature during the first experiment varied from about $-3^{\circ} \mathrm{C}$ to $-5^{\circ} \mathrm{C}$, and during the second experiment - from $-5^{\circ} \mathrm{C}$ to $-9^{\circ} \mathrm{C}$. Room air, supply, return water temperatures at the beginning of the day were also similar. Reference room temperatures during both experiments varied in the same way.

The response of the heating system, controlled with the proportional controller, is shown in Fig. 10. Fig. 11 shows the response of the heating system controlled by the learning fuzzy controller. The first two graphs of each figure represent the output and

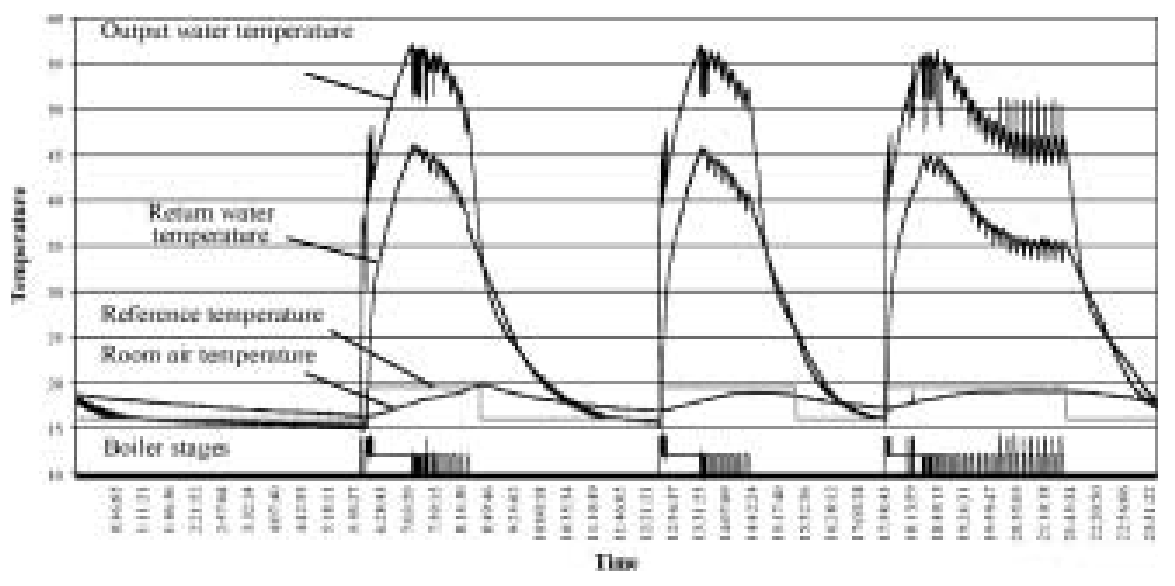

Fig. 10. Heating system response to $\mathrm{P}$ control. 


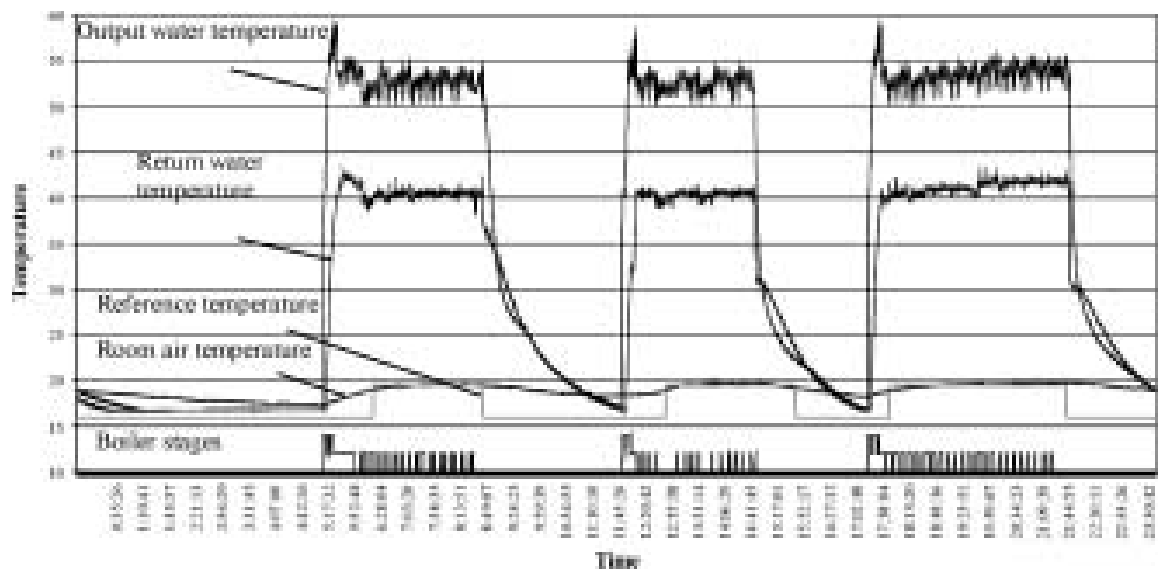

Fig. 11. Heating system's response to learning fuzzy control.

the return water temperatures. Next two graphs represent room temperature set point and current values. The reference room temperature was changed three times per day. The last graph represents boiler state. The peaks represent full heating capacity of the boiler; the middle position indicates the boiler operation at half of the total capacity.

The effectiveness of controllers was evaluated according to three criterions. Comfort level is determined by calculating the average deviation of room temperature from the room reference temperature, when the room temperature is in raised states, according to formula 3 , where $x_{i}$ is the room temperature, and $\bar{x}$ is the reference room temperature. $N$ is the number of records. Gas consumption and On/Off switching times are calculated for the whole experiment time -24 hours. On/Off switching rate is determined calculating how many times boiler stages were activated during the day. Calculation results are presented in the Table 3.

According to the Table 3, the comfort level in the system controlled with the proposed learning fuzzy controller is 7.25 times higher than in the system controlled with the conventional P controller. Gas consumption is 1.28 times smaller and the boiler switching on and off times is 1.39 times smaller in case of fuzzy control, so the overall performance of learning fuzzy controller is better.

Table 3

Performance criterions

\begin{tabular}{lcc}
\hline \multicolumn{1}{c}{ Criterions } & Proportional controller & Fuzzy controller \\
\hline Comfort level & 1.408 & 0.194 \\
Gas consumption per day & $7.36 \mathrm{~m}^{3}$ & $5.75 \mathrm{~m}^{3}$ \\
On/Off switching rate & 100 & 72 \\
\hline
\end{tabular}




\section{Conclusions}

In this paper general learning fuzzy controller's design strategy was presented and applied for the synthesis of the learning fuzzy controllers for two nonlinear processes: the level/pressure process and the heating system. The efficiency of the synthesized controllers was experimentally tested and compared with the other controllers. The results of the experiments prove the ability of the synthesized fuzzy controllers to identify the characteristics of nonlinear plants and to learn to control them at different operating regimes. The results also prove the advantage of proposed learning fuzzy controllers over the conventional and non-learning fuzzy (in case of level-pressure control) controllers.

\section{References}

Abonyi, J. (2003). Fuzzy Model Identification for Control. Birkhauser, USA.

Chen, G., and T.T. Pham (2001). Introduction to Fuzzy Sets, Fuzzy Logic, and Fuzzy Control Systems, CRC Press, New York.

Cox, E. (1994). The Fuzzy Systems Handbook: A Practitioner's Guide to Building, Using, and Maintaining Fuzzy Systems. Academic Press, New York.

Driankov, D., and R. Palm (1998). Advances in Fuzzy Control. Physica-Verlag Heidelberg, New York.

Kaminskas, V., and R. Liutkevičius (2002). Adaptive fuzzy control of nonlinear plant with changing dynamics. Informatica, 13(3), 287-298.

Liutkevičius, R. (2003). Coupled adaptive fuzzy control of nonlinear, time-varying plant. Informatica, 14(3), 323-336.

Mamdani, E.H. (1974). Application of fuzzy algorithms for simple dynamic plant. In Proceedings IEE, D-121. pp. 1558-1588.

Ogata, K. (1997). Modern Control Engineering. Prentice-Hall, New Jersey.

Passino, K.M., and S. Yurkovich (1998). Fuzzy Control. Addison-Wesley, USA.

Takagi, T., and M. Sugeno (1985). Fuzzy identification of systems and its applications to modeling and control. IEEE Trans. on Systems, Man, and Cybernetics, 15(1), 116-132.

Zadeh, L.A. (1965). Fuzzy sets. Information and Control, 8, 338-353. 
V. Kaminskas graduated from Kaunas Polytechnic Institute 1968. From 1968 to 1989 he worked in the Institute of Physical and Technical Problems of Energy Research at the Lithuanian Academy of Science. His doctoral (1972) and habilitated doctor's (1983) degree dissertations are in the field of control systems and theory of information. In October 1989 he was appointed director of the Informatics Science Center of Vytautas Magnus University (VMU), in May 1990 he was elected dean of the Faculty of Informatics, and in September 1990 he became vice-rector of VMU. In December 1996 he was elected rector of VMU, and in May 2001 re-elected for a second 5-year term. Since 1991 prof. V. Kaminskas has been an expert-member of the Lithuanian Academy of Sciences. In 1998 he was elected corresponding member of Lithuanian Academy of Sciences. Prof. V. Kaminskas scientific interests include computer aided simulations, identification, control and diagnostic systems. He has published 4 books and over 200 scientific papers.

R. Liutkevičius graduated from Faculty of Informatics, Vytautas Magnus University (VMU) in 1996. In 1998 he received master degree at the Faculty of Informatics, VMU. His doctoral dissertation, defended in 2003 at VMU, is in the field of adaptive fuzzy control systems. His research interest is in adaptive fuzzy control, system identification and modeling. 


\section{Netiesiniu procesu neraiškia logika pagristas mokslus valdymas}

Vytautas KAMINSKAS, Raimundas LIUTKEVIČIUS

Straipsnyje nagrinejamas netiesinio objekto valdymas neraiškios logikos reguliatoriais. Pasiūlyta bendra mokslaus neraiškia logika pagrịsto reguliatoriaus struktūra, kur eksperto patirtis ir žinios panaudojamos reguliatoriaus mokymo algoritmų sudarymui, o ne valdymo taisykliu formulavimui, ir parodytas tokio reguliatoriaus pritaikymas dviejuose netiesinio valdymo uždaviniuose: vandens lygio ir oro slègio valdyme, bei šildymo sistemos valdyme. Eksperimentiškai parodytas ir palygintas su kitais reguliatoriais pasiūlytos struktūros reguliatorių pakankamas efektyvumas. 